\title{
Drugs of Abuse Specifically Sensitize Noradrenergic and Serotonergic Neurons Via a Non-Dopaminergic Mechanism
}

\author{
Christophe Lanteri' ${ }^{1,2}$, Lucas Salomon ${ }^{1,2}$, Yvette Torrens', Jacques Glowinski' and Jean-Pol Tassin*,1 \\ IInstitut National de la Santé et de la Recherche Médicale Unité I I4, Centre National de la Recherche Scientifique UMR 7/48, Collège \\ de France, Paris Cedex, France
}

\begin{abstract}
A challenge in drug dependence is to delineate long-term neurochemical modifications induced by drugs of abuse. Repeated $d$ amphetamine was recently shown to disrupt a mutual regulatory link between noradrenergic and serotonergic neurons, thus inducing long-term increased responses to $d$-amphetamine and para-chloroamphetamine, respectively. We show here that such a sensitization of noradrenergic and serotonergic neurons also occurs following repeated treatment with cocaine, morphine, or alcohol, three compounds belonging to main groups of addictive substances. In all cases, this sensitization is prevented by $\alpha$ lb-adrenergic and 5 - $\mathrm{HT}_{2 \mathrm{~A}}$ receptors blockade, indicating the critical role of these receptors on long-term effects of drugs of abuse. However, repeated treatments with two non-addictive antidepressants, venlafaxine, and clorimipramine, which nevertheless inhibit noradrenergic and serotonergic reuptake, do not induce noradrenergic and serotonergic neurons sensitization. Similarly, this sensitization does not occur following repeated treatments with a specific inhibitor of dopamine (DA) reuptake, GBRI2783. Moreover, we show that the effects of SCH23390, a DI receptor antagonist known to inhibit development of $d$-amphetamine behavioral sensitization, are due to its 5 - $\mathrm{HT}_{2 \mathrm{C}}$ receptor agonist property. SCH23390 blocks amphetamine-induced release of norepinephrine and RSI0222I, a 5- $\mathrm{HT}_{2 \mathrm{C}}$ antagonist, can reverse this inhibition as well as inhibition of noradrenergic sensitization and development of behavioral sensitization induced by repeated $d$ amphetamine. We propose that noradrenergic/serotonergic uncoupling is a common neurochemical consequence of repeated consumption of drugs of abuse, unrelated with DA release. Our data also suggest that compounds able to restore the link between noradrenergic and serotonergic modulatory systems could represent important therapeutic targets for investigation.
\end{abstract} Neuropsychopharmacology (2008) 33, I724- 1734; doi: I 0. I 038/sj.npp. I 30I548; published online 5 September 2007

Keywords: cocaine; morphine; alcohol; antidepressants; microdialysis; prefrontal cortex

\section{INTRODUCTION}

One of the main challenges facing the field of drug abuse is to understand why human addicts relapse after long periods of withdrawal, even when they are aware of the adverse consequences of their behavior. It is generally assumed that drugs abused by humans, including psychostimulants and opiates, preferentially increase dopamine (DA) concentration in a subcortical area, the nucleus accumbens (Di Chiara and Imperato, 1988; Wise, 1998; Koob et al, 1998; Everitt and Wolf, 2002). A pleasure may indeed result from the dopaminergic stimulation of different cerebral structures composing the 'reward system'. As noted by Robinson and Berridge (1993, 2000), the 'drug-liking' attitude in humans progressively becomes a 'drug-wanting' behavior, a transition which, in certain individuals, gives rise to drug craving.

*Correspondence: Dr J-P Tassin, Department of Neuropharmacology, CNRS UMR7I48, Collège de France, II, Place Marcelin Berthelot, 7523। Paris Cedex 05, France, Tel: + 33 | 4427|23।, Fax: + 33 । 4427| 260, E-mail: jean-pol.tassin@college-de-france.fr

${ }^{2}$ These authors contributed equally to this work.

Received I5 May 2007; revised 10 July 2007; accepted 17 July 2007
Despite the critical role of DA in the effects of drugs of abuse, some data indicate, however, that noradrenergic rather than dopaminergic transmission is necessary for morphine-induced reward (Drouin et al, 2002b; Hnasko et al, 2005; Ventura et al, 2005; Olson et al, 2006). Whatever the hypothesis, it has been shown that addictive drugs share the ability to induce long-lasting cellular adaptations in neural systems, such as alterations in gene expression (Hyman and Malenka, 2001; Nestler, 2001). In rodents, evidence of these enduring adaptations includes the development of a behavioral sensitization, that is the progressive enhancement in behavioral responding, such as locomotor hyperactivity, to repeated injections of an opiate or a psychostimulant (Robinson and Berridge, 1993). We have recently shown that repeated injections of $d$-amphetamine in C57Bl6 mice induce the dissociation of a mutual regulation between noradrenergic and serotonergic neurons. This phenomenon, called uncoupling, results in a hyper-reactivity, or sensitization, of noradrenergic and serotonergic neurons (Salomon et al, 2006). Briefly, reactivity of noradrenergic neurons was tested by measuring cortical extracellular norepinephrine (NE) following injection of $d$-amphetamine, whereas, because $d$-amphetamine did not release serotonin 
(5-HT) in our experimental conditions, reactivity of serotonergic neurons was monitored by measuring cortical extracellular 5-HT levels following injection of parachloroamphetamine (PCA), a 5-HT releaser. PCA is a compound analogous to ecstasy, which induces locomotor hyperactivity in mice (Itzhak et al, 2004). Four days after exposure to a regimen of four once-daily injections of $d$-amphetamine, cortical noradrenergic and serotonergic responses to the respective injections of $d$-amphetamine and PCA were enhanced. Increased responding remained elevated for at least 1 month. Moreover, both the $d$-amphetamine-induced increases in cortical NE levels and behavioral sensitization were not observed when animals were pretreated, before each of the four once-daily injections of $d$-amphetamine, with prazosin and SR 46349B, two antagonists of $\alpha 1 \mathrm{~b}$-adrenergic and $5-\mathrm{HT}_{2 \mathrm{~A}}$ receptors, respectively, suggesting that stimulation of both receptors was necessary for the development of this sensitization (Salomon et al, 2006). The present experiments assessed whether the same uncoupling of NE-5-HT activity is produced following the exposure to compounds belonging to main groups of drugs of abuse, that is cocaine, morphine, and ethanol. The effect of exposure to clorimipramine or venlafaxine, two antidepressants that stimulate noradrenergic and serotonergic transmissions but do not induce substance dependence nor behavioral sensitization (Mitchell et al, 2006), was also assessed. Similarly, in an effort to unravel the mechanism of this uncoupling, the effect of exposure to GBR 12783, a specific DA reuptake inhibitor was tested. Finally, because the stimulation of D1 receptors was often shown to be critical in the effects of drugs of abuse (Vezina and Stewart, 1989; Hamamura et al, 1991; Jeziorski and White, 1995), we have analyzed the effects of $\mathrm{SCH} 23390$, the D1 receptor antagonist generally used in these experiments, to explore its role on noradrenergic and serotonergic transmissions.

\section{MATERIALS AND METHODS}

\section{Subjects}

Wild type (WT) mice were C57Bl6 male adult (25-35 g). They were maintained on a 12-h light/dark cycle (lights on at 0700 ) with food and water freely available.

\section{Drugs}

$d$-Amphetamine sulfate, $p$-chloroamphetamine hydrochloride, cocaine chlorhydrate (Sigma Aldrich, L'Isle d'Abeau-Chesne, France), morphine chlorhydrate (from Francopia), and ethanol ( $2 \mathrm{~g} / \mathrm{kg}$ in $25 \% \mathrm{v} / \mathrm{v})$ were dissolved in saline. Venlafaxine (generous gift from Wyeth Laboratories, Madison, NJ) and clorimipramine chlorhydrate (Sigma Aldrich) were dissolved in saline and distilled water, respectively. Prazosin hydrochloride (Sigma Aldrich) was sonicated in water and completed with saline. SR46349B hemifumarate $\{(1 Z, 2 \mathrm{E})-1$-(2-fluoro-phenyl)-3-(4-hydroxyphenyl)-prop-2-en-one-O-(2-dimethylamino-ethyl)-oxime hemifumarate $\}$ was a generous gift from Laboratories Sanofi-Synthelabo (Montpellier, France). It was dissolved with a drop of lactic acid, neutralized with $1 \mathrm{M} \mathrm{NaOH}$, and sonicated in saline. SCH23390 was purchased from
Sigma Aldrich (L'Isle d'Abeau-Chesne, France) and was first dissolved in distilled water, which was completed with saline. RS102221 (\{8-[5-(2,4-dimethoxy-5-(4-trifluoromethylphenylsulfonamido) phenyl-5-oxopentyl)]-1,3,8triazaspiro[4.5]decane-2,4-dione hydrochloride\}, Tocris, Bristol, UK), a specific $5-\mathrm{HT}_{2 \mathrm{C}}$ receptor antagonist, was dissolved in DMSO and completed with saline in order to obtain a dose of $2 \mathrm{mg} / \mathrm{kg}$ (Bonhaus et al, 1997; Conductier et al, 2005). This compound demonstrated a nearly 100 -fold selectivity for the $5-\mathrm{HT}_{2 \mathrm{C}}$ receptor as compared with the $5-\mathrm{HT}_{2 \mathrm{~A}}$ and 5- $\mathrm{HT}_{2 \mathrm{~B}}$ receptors (Bonhaus et al, 1997). All drugs were injected intraperitoneally $(0.3 \mathrm{ml}$ per $100 \mathrm{~g})$. GBR 12783 was synthesized by $\operatorname{Pr}$ Robba (Caen, France) and was dissolved in DMSO $(<5 \%)$. Doses are expressed as salts. $d$-Amphetamine was given at $2 \mathrm{mg} / \mathrm{kg}$ and $p$-chloroamphetamine at $7 \mathrm{mg} / \mathrm{kg}$ (Itzhak et al, 2004). Doses of prazosin $(1 \mathrm{mg} / \mathrm{kg}$, i.p.) and SR46349B (1 mg/kg, i.p.) were kept identical to previous experiments (Salomon et al, 2006).

\section{Locomotor Activity}

Acute treatment. Mice were introduced in a circular corridor $(4.5 \mathrm{~cm}$ width, $17 \mathrm{~cm}$ external diameter) crossed by four infrared beams $(1.5 \mathrm{~cm}$ above the base) placed at every $90^{\circ}$ (Imetronic, Pessac, France). The locomotor activity was counted when animals interrupted two successive beams and thus had traveled a quarter of the circular corridor. Spontaneous activity was recorded for $60 \mathrm{~min}$ (habituation to the experimental procedure) then mice were injected intraperitoneally with $d$-amphetamine or $p$-chloroamphetamine and locomotor responses were recorded for an additional $200 \mathrm{~min}$ period.

Repeated treatment. The time course of the repeated treatments performed before locomotor activity recording is shown in Table 1. Briefly, mice were injected on 4 consecutive days with cocaine $(20 \mathrm{mg} / \mathrm{kg})$, morphine $(20 \mathrm{mg} / \mathrm{kg})$, ethanol $(2 \mathrm{~g} / \mathrm{kg})$, venlafaxine $(20 \mathrm{mg} / \mathrm{kg})$, clorimipramine (20 mg/kg), GBR12783 (20 mg/kg), and $d$-amphetamine $(2 \mathrm{mg} / \mathrm{kg})$ with or without SCH23390 (0.2 mg/kg) and/or RS102221 (2 mg/kg) and their locomotor activity was recorded following a $d$-amphetamine injection after a 4-day withdrawal with the same protocol as for an acute treatment. To test the effect of the pretreatment on the development of behavioral sensitization, mice received every single day a pretreatment (saline or prazosin + SR46349B) $30 \mathrm{~min}$ before the injection of cocaine, morphine, or ethanol. When animals received prazosin + SR46349B as a pretreatment before morphine or ethanol, two subsequent injections of prazosin were administered at 60 and $150 \mathrm{~min}$ after drug injection, because of the long-lasting effects of morphine and ethanol and the short half-life $(100 \mathrm{~min}$ ) of prazosin (Auclair et al, 2004). Finally, locomotor responses to $d$-amphetamine or PCA were tested 4 days after the last drug injection. Control mice were injected on 4 consecutive days with $0.9 \%$ saline $(0.1 \mathrm{ml} /$ injection $)$ and their locomotor response to $d$-amphetamine (or PCA) was recorded 4 days later.

\section{Surgery}

Mice were anesthetized with sodium pentobarbital (60 mg/kg; Sanofi Santé Animale, France) and placed in a 
Table I Time Course of Repeated Treatments Performed before Analysis of Cortical Extracellular NE and 5-HT Levels and Locomotor Responses Induced by d-Amphetamine or Para-Chloroamphetamine Injections

\begin{tabular}{|c|c|}
\hline Day & Treatment \\
\hline \multicolumn{2}{|c|}{ Microdialysis } \\
\hline 0 & Surgery \\
\hline \multirow[t]{2}{*}{4} & $\begin{array}{l}t=0 \text { Sal or } \mathrm{SR}+\mathrm{Pz} \text { or } \\
\mathrm{SCH} \text { or } \mathrm{SCH}+\mathrm{RS} \text { or RS }\end{array}$ \\
\hline & $\begin{array}{l}t=30^{\prime} \text { Sal or Coc or Morph or Alcohol or } \\
\text { Antidep or GBR or Amph }\end{array}$ \\
\hline 5 & Idem day 4 \\
\hline 6 & Idem day 4 \\
\hline 7 & Idem day 4 \\
\hline 11 & $\begin{array}{l}\text { Microdialysis and systemic Sal or Amph or } \\
\text { PCA after basal values stabilization. }\end{array}$ \\
\hline \multicolumn{2}{|c|}{ Locomotor activity } \\
\hline 0 & $\begin{array}{l}t=-60^{\prime} \text { Introduction in the apparatus } \\
t=0 \text { Sal or } \mathrm{SR}+\mathrm{Pz} \text { or } \mathrm{SCH} \text { or } \mathrm{SCH}+\mathrm{RS} \text { or RS } \\
t=30^{\prime} \mathrm{Sal} \text { or Coc or Morph or Alcohol or Amph }\end{array}$ \\
\hline । & Idem day 0 \\
\hline 2 & Idem day 0 \\
\hline 3 & Idem day 0 \\
\hline 7 & $\begin{array}{l}t=-60^{\prime} \text { Introduction in the apparatus } \\
t=0 \text { Sal or systemic Amph or PCA }\end{array}$ \\
\hline
\end{tabular}

Abbreviations: Amph, $d$-amphetamine; Antidep, antidepressants (venlafaxine and clorimipramine); Coc, cocaine; GBR, GBRI2783; Morph, morphine; PCA, para-chloroamphetamine; Pz, prazosin; RS, RSI 0222I; SCH, SCH23390; SR, SR46349B.

Animals received four identical treatments every day during 4 days before microdialysis and locomotor recording, which occurred after a 4-day withdrawal.

stereotaxic frame (Kopf instruments). Unilateral permanent cannula (CMA/7 guide cannula, Microdialysis AB, Sweden) was placed at the edge of the PFC and was secured on the skull with screw and dental cement. The coordinates for the guide cannula tip were anteroposterior: +2.6 relative to bregma, medio-lateral: +0.5 , and dorso-ventral: $0 \mathrm{~mm}$ from dura (Salomon et al, 2006). After surgery, mice were placed in individual plastic cages and allowed to recover for at least 4 days.

\section{Microdialysis Experiment}

Acute treatment. On the day of the experiment, the microdialysis probe was inserted in the PFC (CMA/7, membrane length $2 \mathrm{~mm}$ and diameter $0.24 \mathrm{~mm}$, cutoff: $6000 \mathrm{Da}$, Microdialysis AB, Sweden). Artificial CSF (in mM: $\mathrm{NaCl}: 147 ; \mathrm{KCl}: 3.5 ; \mathrm{CaCl}_{2}: 1 ; \mathrm{MgCl}_{2}: 1.2, \mathrm{NaH}_{2} \mathrm{PO}_{4}: 1$; $\mathrm{NaHCO}_{3}: 25, \mathrm{pH}=7.6$ ) was perfused with a CMA100 microinjection pump through the probe at a rate of $1 \mu \mathrm{l} / \mathrm{min}$ via FEP catheter (internal diameter $0.12 \mathrm{~mm}$ ) connected to a fluid swivel. Adequate steady state of monoamines levels in perfusate samples was reached $140 \mathrm{~min}$ after probe insertion, and samples were collected in $300 \mu$ l vials placed into a refrigerated computer-controlled fraction collector (CMA/170).
Samples (20 $\mu$ l every $20 \mathrm{~min})$ were collected during $100 \mathrm{~min}$, to determine basal extracellular monoamines values. Following $d$-amphetamine, SCH23390 $+d$-amphetamine, $\mathrm{SCH} 23390+$ $\mathrm{RS} 102221+d$-amphetamine, and RS102221 + $d$-amphetamine or PCA and SCH $23390+$ PCA injections, samples were collected for $200 \mathrm{~min}$. SCH23390 and RS102221 were injected $30 \mathrm{~min}$ before $d$-amphetamine or PCA. Samples were analyzed for NE or 5-HT levels on the day of the experiment.

Repeated treatment. The time course of the repeated treatments performed before microdialysis analysis is shown in Table 1. Briefly, mice received four consecutive daily injections of pretreatment plus cocaine, morphine, or ethanol and waited 4 days before the dialysis experiment. Every day after drug injection, mice were immediately placed for $2 \mathrm{~h}$ in the cylindrical compartment used to perform microdialysis. Control mice received four consecutive daily injections of $0.9 \%$ saline $(0.1 \mathrm{ml} /$ injection $)$ and waited 4 days before the dialysis experiment.

\section{Biochemistry}

Dialysate samples were completed to $30 \mu \mathrm{l}$ with the adapted mobile phase and placed into a refrigerated automatic injector (Triathlon, Spark Holland, Emmen, The Netherlands). The samples $(25 \mu \mathrm{l})$ were injected every $30 \mathrm{~min}$ through a rheodyne valve in the mobile phase circuit. High-performance liquid chromatography was performed with a reverse-phase column $(80 \times 4.6 \mathrm{~mm}, 3 \mu \mathrm{M}$ particle size, HR-80, ESA Inc., Chelmsford, MA). Mobile phase (for $\mathrm{NE}$ analysis: $\mathrm{NaH}_{2} \mathrm{PO}_{4} 0.1 \mathrm{M}$, EDTA $0.1 \mathrm{mM}$, octane sulfonic acid $3.8 \mathrm{mM}$, triethylamine $0.25 \mathrm{mM}$, methanol $10 \%$, pH 2.9 and for 5-HT analysis: $\mathrm{NaH}_{2} \mathrm{PO}_{4} 0.1 \mathrm{M}$, EDTA $0.1 \mathrm{mM}$, octane sulfonic acid $1.5 \mathrm{mM}$, triethylamine $0.25 \mathrm{mM}$, methanol $15 \%$, acetonitrile $5 \%, \mathrm{pH} 2.9$ ) was delivered at $0.7 \mathrm{ml} /$ min by an ESA-580 pump. Electrochemical detection was performed with an ESA coulometric detector (Coulochem II 5100A, with a 5014B analytical cell; Eurosep, Cergy, France). The conditioning electrode was set at $-0.175 \mathrm{mV}$, and the detecting electrode was set at $+0.175 \mathrm{mV}$, allowing a good signal-to-noise ratio. External standards were regularly injected to determine the stability of the sensitivity $(0.2 \mathrm{pg}$ for $\mathrm{NE}$ and $0.3 \mathrm{pg}$ for $5-\mathrm{HT}$ ).

\section{Histology}

At the end of the experiment, brains were put into a formaldehyde solution and cut on a microtome in serial coronal slices according to the atlas of Paxinos and Franklin (Paxinos and Franklin, 2001). Histological examination of cannula tip placement was subsequently made on $100-\mu \mathrm{m}$ safranine stained coronal sections.

\section{Statistics}

Statistical analysis was performed using Graph Pad Prism 3.0 software (San Diego, CA). Data from microdialysis and locomotor activity experiments were described as a function of time. Data from microdialysis were expressed as a percentage of the respective mean basal value. The extracellular monoamines levels and the locomotor activity obtained 
after the $d$-amphetamine or PCA injection (100-min analysis) were compared and analyzed with two-way ANOVA (repeated measures). Pharmacological treatments correspond to independent groups of animals. Significant differences were set at $P<0.05$.

\section{RESULTS}

\section{Repeated Saline does not Sensitize Noradrenergic and Serotonergic Neurons}

As expected (Salomon et al, 2006), acute $d$-amphetamine $(2 \mathrm{mg} / \mathrm{kg})$ induced an increase in cortical extracellular NE levels as well as a locomotor response (Figures 1-3, a and b, respectively). Similarly, PCA $(7 \mathrm{mg} / \mathrm{kg})$ also induced an increase in cortical extracellular 5-HT levels and a slight locomotor hyperactivity and (Figures 1-3, c and d, respectively). Repeated injections of saline did not modify increases in cortical extracellular NE and 5-HT levels induced by $d$-amphetamine and PCA, respectively $(F(1,24)=1.939$, $P=0.1765$ and $F(1,24)=3.473, P=0.0747$, for $\mathrm{NE}$ and 5-HT, respectively). However, animals repeatedly treated with saline exhibited a slight but significantly higher locomotor response to $d$-amphetamine and PCA than acutely treated animals $(F(1,20)=8.777, P=0.0036$ and $F(1,20)=11.40, P=0.0009$, for $d$-amphetamine and PCA, respectively).

\section{Repeated Cocaine Sensitizes Noradrenergic and Serotonergic Neurons}

Because of cross-sensitization (Robinson and Berridge, 1993), repeated injections of cocaine $(20 \mathrm{mg} / \mathrm{kg}) \mathrm{led}$, in comparison with animals repeatedly treated with saline, to an enhanced locomotor response to $d$-amphetamine $(F(1,20)=540.6, P<0.0001)$ (Figure 1b). In parallel, $d$ amphetamine increased cortical extracellular NE levels by $87 \%$ in mice repeatedly treated with cocaine when compared with animals repeatedly treated with saline $(F(1,5)=67.35$, $P<0.0001$ ) (Figure 1a).

Interestingly, these animals repeatedly treated with cocaine also exhibited a hyperlocomotor response to PCA $(F(1,20)=313.3, P<0.0001)$ and an increase of $73 \%$ in cortical extracellular 5-HT levels following a PCA injection $(F(1,5)=37.41, \quad P<0.0001$ when compared to animals repeatedly treated with saline) (Figure $1 \mathrm{~b}$ and $\mathrm{d}$ ).

The same experiments were then performed in animals pretreated with prazosin $(1 \mathrm{mg} / \mathrm{kg})$ and SR46349B $(1 \mathrm{mg} / \mathrm{kg})$ before each of the regimen of cocaine. Those pretreatments completely blocked the enhanced neurochemical and behavioral responses to $d$-amphetamine and PCA induced by cocaine (Figure 1a-d).

\section{Repeated Morphine Sensitizes Noradrenergic and Serotonergic Neurons}

As found with cocaine, repeated injections of morphine $(20 \mathrm{mg} / \mathrm{kg})$ led, in comparison with animals repeatedly treated with saline, to an enhanced locomotor response to $d$-amphetamine $(F(1,20)=167.8, P<0.0001)$ (Figure $2 c$ ). Similarly, $d$-amphetamine increased cortical extracellular NE levels by $73 \%$ in mice repeatedly treated with morphine when compared with animals repeatedly treated with saline $(F(1,5)=27.25, P<0.0001$ ) (Figure 2a).

Animals repeatedly treated with morphine also exhibited a hyperlocomotor response to PCA $(F(1,147)=$

\section{Cocaine}
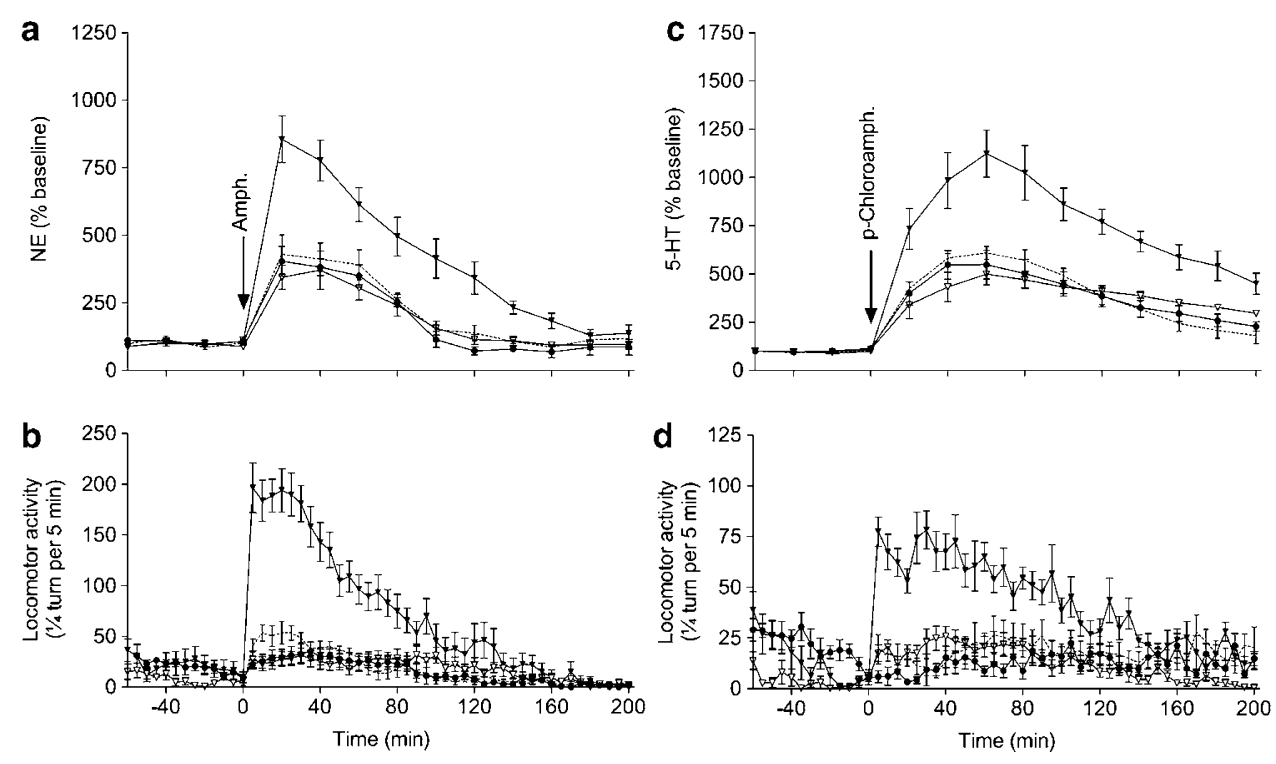

- acute $\quad \cdots .$. repeated saline $\rightarrow$ repeated cocaine $\rightarrow$-repeated SR/Pz + cocaine

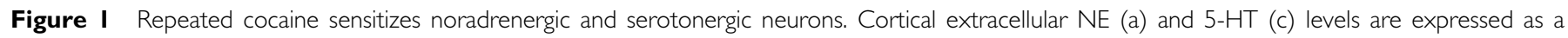

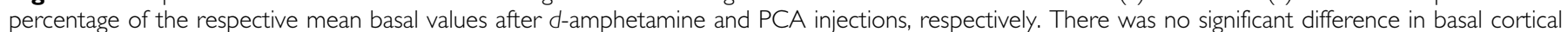

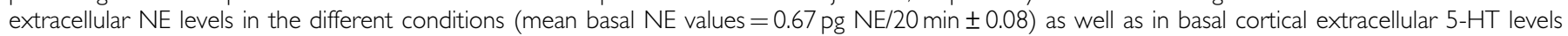

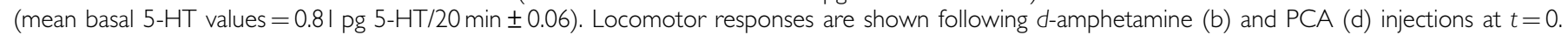
Each group contained eight animals to determine locomotor activity and five animals in microdialysis experiments. 


\section{Morphine}
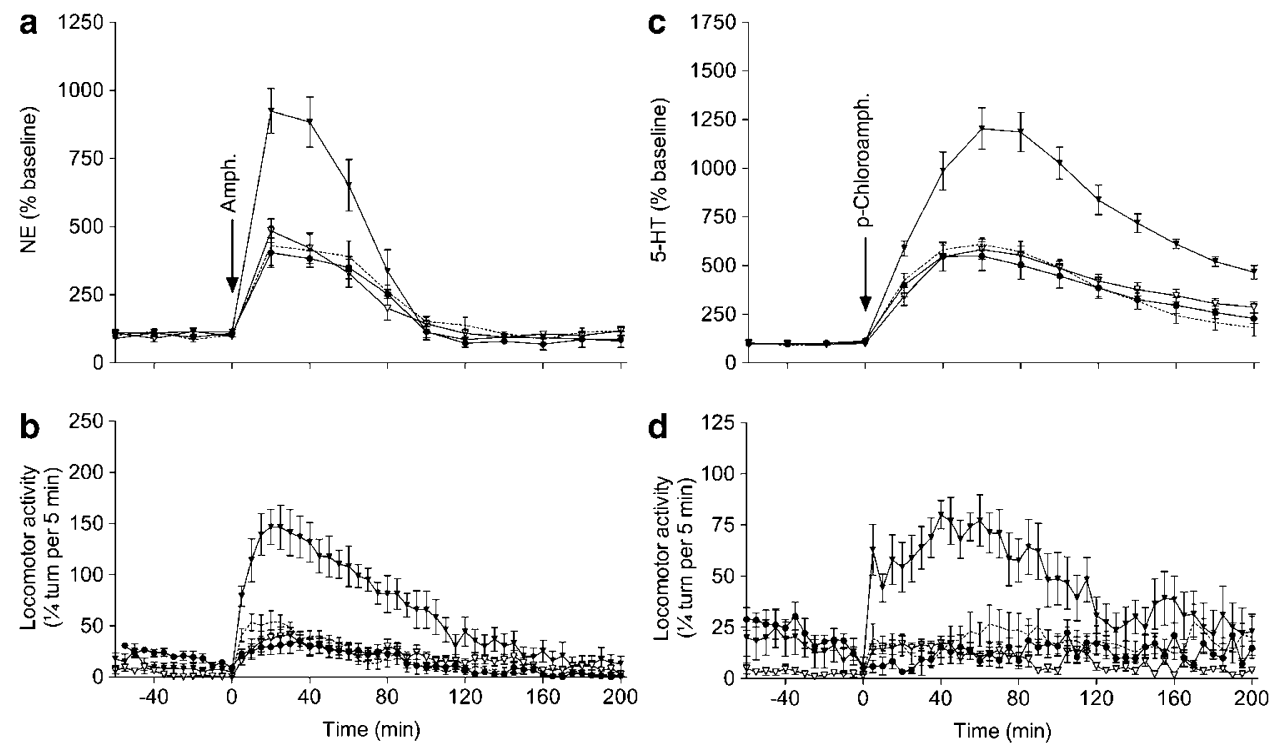

$\rightarrow$ acute $\quad \cdots . .$. repeated saline $\rightarrow$ repeated morphine $\rightarrow-$ repeated SR/Pz + morphine

Figure 2 Repeated morphine sensitizes noradrenergic and serotonergic neurons. Cortical extracellular NE (a) and 5-HT (c) levels are expressed as a percentage of the respective mean basal values after $d$-amphetamine and PCA injections, respectively. Mean basal values were not significantly different from those of Figure I. Locomotor responses are shown following $d$-amphetamine (b) and PCA (d) injections at $t=0$. Each group contained eight animals to determine locomotor activity and five animals in microdialysis experiments.

\section{Ethanol}
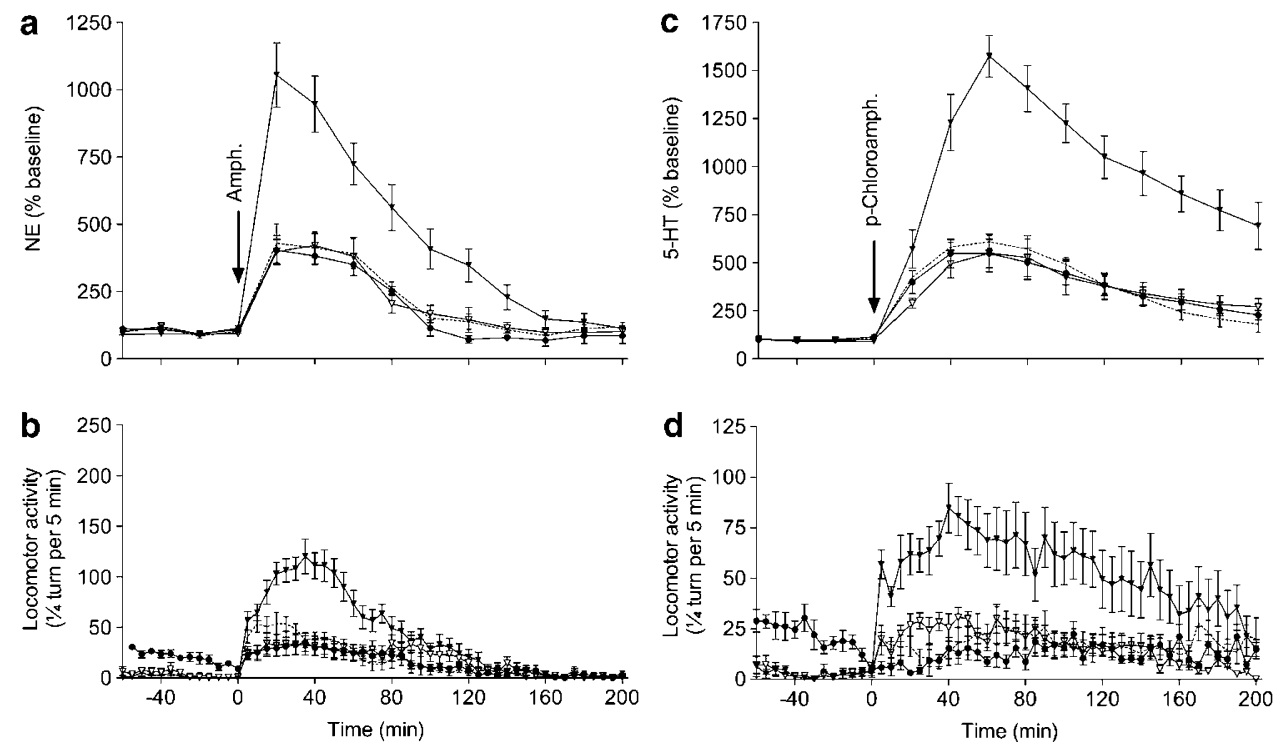

- acute $\quad \cdots-$ repeated saline $\rightarrow$ repeated ethanol $\rightarrow$-repeated SR/Pz + ethano

Figure 3 Repeated ethanol sensitizes noradrenergic and serotonergic neurons. Cortical extracellular NE (a) and 5-HT (c) levels are expressed as a percentage of the respective mean basal values after $d$-amphetamine and PCA injections, respectively. Mean basal values were not significantly different from those of Figure I. Locomotor responses are shown following $d$-amphetamine (b) and PCA (d) injections at $t=0$. Each group contained eight animals to determine locomotor activity and five animals in microdialysis experiments.

$268.8, P<0.0001)$ as well as an increase of $83 \%$ in cortical extracellular 5-HT levels following a PCA injection $(F(1,5)=37.41, P<0.0001$ when compared with animals repeatedly treated with saline) (Figure $2 b$ and $d$ ).
The same experiments were then performed in animals pretreated with prazosin (see Materials and methods) and SR46349B before each of the regimen of morphine. Those pretreatments completely blocked the enhanced 
neurochemical and behavioral responses to $d$-amphetamine and PCA induced by morphine (Figure $2 \mathrm{a}-\mathrm{d}$ ).

\section{Repeated Ethanol Sensitizes Noradrenergic and Serotonergic Neurons}

Four once-daily repeated injections of ethanol $(2 \mathrm{~g} / \mathrm{kg})$ led to a potent cross-sensitization to $d$-amphetamine. Indeed, in comparison with animals repeatedly treated with saline, repeated injections of ethanol enhanced locomotor response to $d$-amphetamine $(F(1,20)=284.1, P<0.0001)$ (Figure 3c) and increased by $118 \%$ cortical extracellular NE levels in response to $d$-amphetamine $(F(1,5)=67.58, P<0.0001$ when compared with animals repeatedly treated with saline) (Figure 3a).

Similarly, those animals repeatedly treated with ethanol exhibited a hyperlocomotor response to PCA $(F(1,147)=$ $180.2, P<0.0001$ ) (Figure 3b) as well as a $119 \%$ increase in cortical extracellular 5-HT levels following a PCA injection $(F(1,5)=141.6, P<0.0001$ when compared with animals repeatedly treated with saline) (Figure $3 \mathrm{~d}$ ).

The same experiments were then performed in animals pretreated with prazosin (see Materials and methods) and SR46349B before each of the regimen of ethanol. Those pretreatments completely blocked the enhanced neurochemical and behavioral responses to $d$-amphetamine and PCA induced by ethanol (Figure 3a-d).

Repeated Venlafaxine, Clorimipramine, or GBR12783 do not Sensitize Noradrenergic and Serotonergic Neurons

When animals received four once-daily injections of venlafaxine $(20 \mathrm{mg} / \mathrm{kg})$, clorimipramine $(20 \mathrm{mg} / \mathrm{kg})$, or GBR12783 $(20 \mathrm{mg} / \mathrm{kg})$, increases in cortical extracellular $\mathrm{NE}$ and 5-HT levels induced by $d$-amphetamine and PCA were, respectively, similar in repeatedly treated animals and in those repeatedly treated with saline $(F(1,24)=2.197$, $P=0.1513 ; \quad F(1,24)=0.5502, P=0.4654), \quad(F(1,24)=1.566$, $P=0.2229 ; \quad F(1,24)=0.5457, \quad P=0.4643)$, and $(F(1,24=$ $2.324, P=0.1405 ; F(1,24)=0.9531, P=0.3387)$ for venlafaxine, clorimipramine and GBR12783, and NE and 5-HT levels, respectively (Figure $4 \mathrm{a}-\mathrm{f}$ ).

\section{SCH23390, a D1 Receptor Antagonist, Blocks Cortical d-Amphetamine-Induced Extracellular NE Levels by its $5-\mathrm{HT}_{2 \mathrm{C}}$ Agonist Property}

We have shown previously that pretreatment with SCH23390 could block NE-5-HT uncoupling induced by repeated $d$-amphetamine (Salomon et al, 2006). To
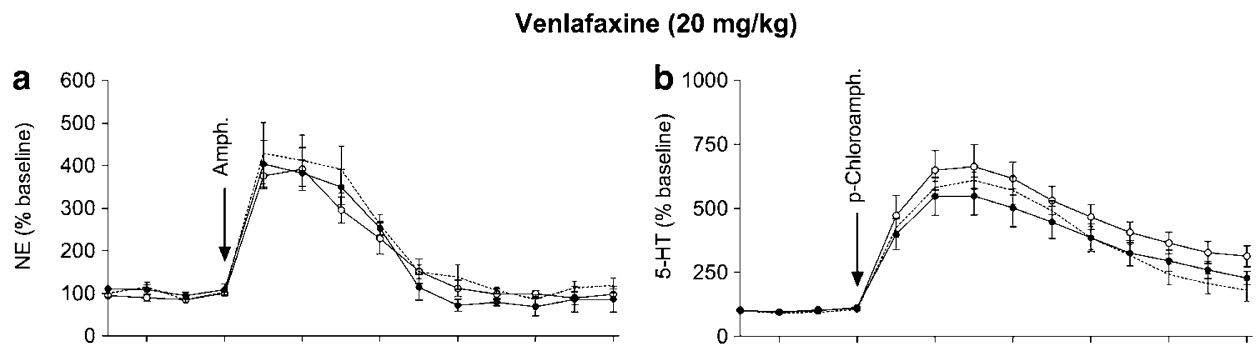

Clorimipramine $(20 \mathrm{mg} / \mathrm{kg})$
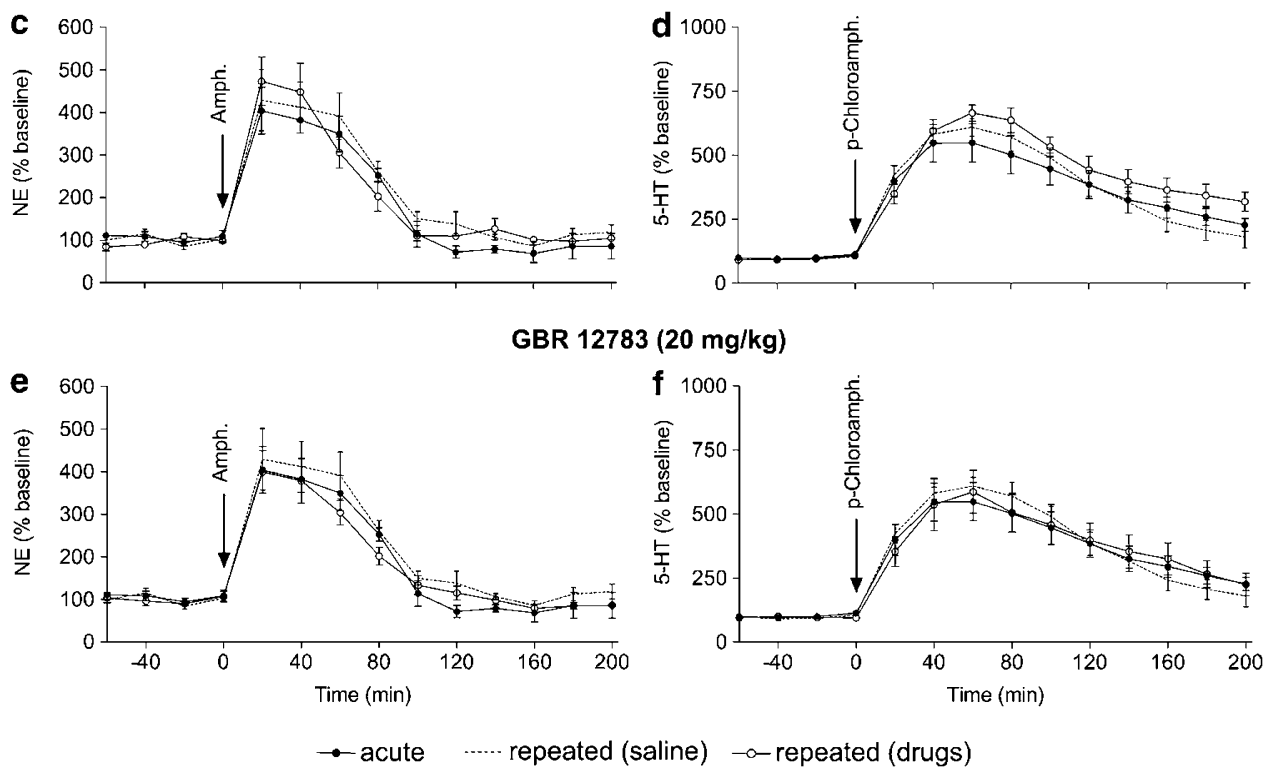

Figure 4 Repeated venlafaxine, clorimipramine, or GBR 12783 do not sensitize noradrenergic and serotonergic neurons. Cortical extracellular NE $(a, c$, and e) and 5-HT (b, d, and f) levels are expressed as a percentage of the respective mean basal values after $d$-amphetamine and PCA injections, respectively. Mean basal values were not significantly different from those of Figure I. Each group contained at least five animals. 

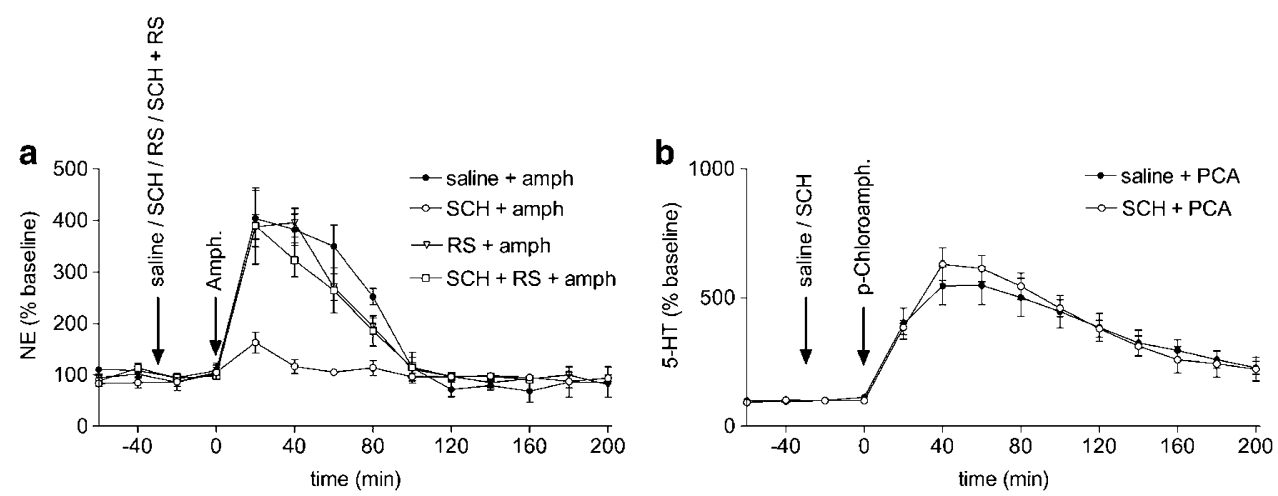

Figure $5 \mathrm{SCH} 23390$, a DI receptor antagonist, blocks cortical d-amphetamine-induced extracellular NE levels by its $5-\mathrm{HT}_{2 \mathrm{C}}$ agonist property. Cortical extracellular NE (a) and 5-HT (b) levels are expressed as a percentage of the respective mean basal values. Mean basal values were not significantly different from those of Figure I. (a) Animals received acutely either saline $+d$-amphetamine (Amph, $2 \mathrm{mg} / \mathrm{kg}$ ), SCH23390 (SCH, $0.2 \mathrm{mg} / \mathrm{kg}$ ) $+d$-amphetamine, RSI0222I (RS, $2 \mathrm{mg} / \mathrm{kg}$ ) + d-amphetamine, or SCH23390 + RSI0222I + d-amphetamine and cortical extracellular NE levels were monitored. (b) Animals received acutely saline + p-chloroamphetamine $(\mathrm{PCA}, 7 \mathrm{mg} / \mathrm{kg}$ ) or SCH + PCA and cortical extracellular 5-HT levels were monitored. Each group contained five animals.

understand the role of $\mathrm{D} 1$ receptors in $d$-amphetamineinduced NE-5-HT uncoupling, acute effects of SCH23390 were analyzed on $d$-amphetamine-induced NE and PCAinduced 5-HT levels. SCH23390 completely blocked the increase in cortical extracellular $\mathrm{NE}$ levels induced by $d$-amphetamine $(F(1,5)=787.8, P<0.0001)$ (Figure 5a). At the opposite, acute SCH23390 had no effect on cortical extracellular 5-HT levels induced by PCA $(F(1,24)=$ $0.01693, P=0.8976$ ) (Figure $5 b$ ). As SCH23390 is also a potent $5-\mathrm{HT}_{2 \mathrm{C}}$ agonist (Millan et al, 2001b), the effects of RS102221, a specific $5 \mathrm{HT}_{2 \mathrm{C}}$ receptor antagonist (Bonhaus et al, 1997), were tested on the increase in cortical extracellular NE levels induced by $d$-amphetamine in the presence of SCH23390. RS102221 completely reversed the effects of SCH23390 on $d$-amphetamine-induced extracellular NE levels as shown by a nonsignificant difference on $d$-amphetamine-induced extracellular $\mathrm{NE}$ levels in saline- and SCH23390 + RS102221-treated animals $(F(1,24)=$ $0.9146, P=0.3484$ ) (Figure 5a). It was finally verified that RS102221 had not, by itself, any effect on $d$-amphetamineinduced extracellular NE levels $(F(1,24)=0.3010, P=0.5883)$ (Figure 5a).

SCH23390 Blocks Amphetamine-Induced Noradrenergic Neurons and Behavioral Sensitization because of its 5- $\mathrm{HT}_{2 \mathrm{C}}$ Agonist Property

As shown previously (Vezina, 1996; Salomon et al, 2006), a pretreatment with $0.2 \mathrm{mg} / \mathrm{kg} \mathrm{SCH} 23390$ completely blocked behavioral sensitization induced by $d$-amphetamine $(F(1,20)=261.7, P<0.0001)$ (Figure 6). However, when the $5-\mathrm{HT}_{2 \mathrm{C}}$ receptor antagonist, $\mathrm{RS} 102221(2 \mathrm{mg} / \mathrm{kg})$, was administered with SCH23390, it restored completely the behavioral sensitization induced by $d$-amphetamine as shown by a nonsignificant difference between locomotor responses to $d$-amphetamine in $d$-amphetamineand $d$-amphetamine + SCH23390 + RS102221-treated animals $(F(1,147)=2.265, P=0.1344)$ (Figure 6a). Similarly, $d$-amphetamine increased cortical extracellular NE levels by $91 \%$ in mice repeatedly treated with $d$-amphetamine + SCH23390 + RS102221 when compared with animals repeatedly treated with saline $(F(1,5)=123.1, P<0.0001)$.
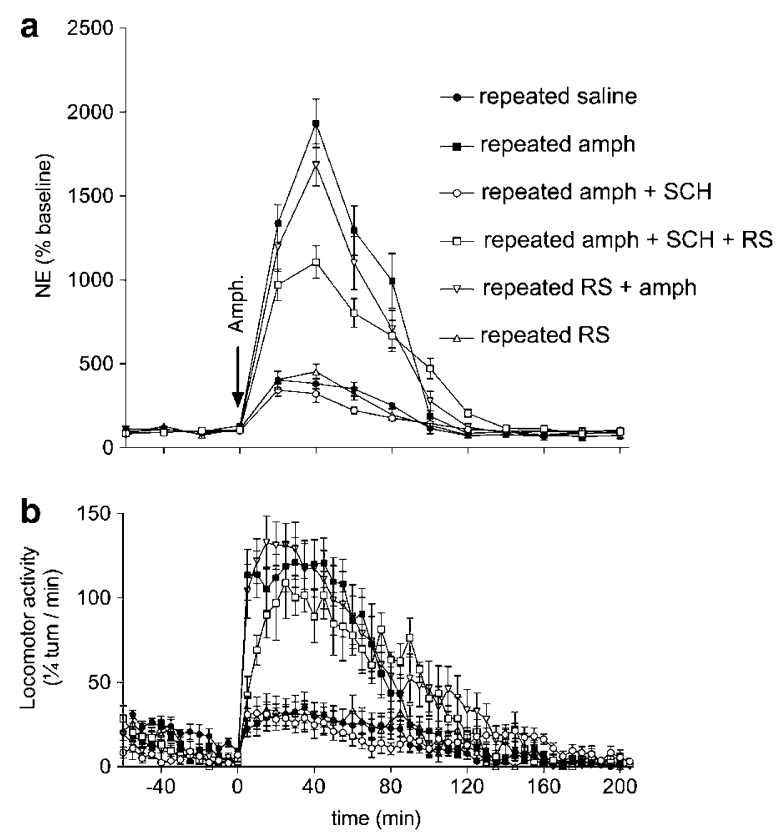

Figure $6 \mathrm{SCH} 23390$ blocks development of behavioral sensitization to d-amphetamine by its $5-\mathrm{HT}_{2 \mathrm{C}}$ agonist property. Animals were treated 4 days by saline, $d$-amphetamine (Amph, $2 \mathrm{mg} / \mathrm{kg}$ ), SCH23390 (SCH, $0.2 \mathrm{mg} /$ $\mathrm{kg})+d$-amphetamine, SCH $23390+\mathrm{RSI} 02221$ (RS, 2 mg/kg) + d-amphetamine, RS + $d$-amphetamine, or RS and were challenged 4 days later with d-amphetamine $(2 \mathrm{mg} / \mathrm{kg})$. In (a), cortical extracellular NE levels were monitored, each group containing five animals. In (b), locomotor activity was measured, each group containing eight animals.

This effect was, however, significantly lower than that obtained with repeated treatments with $d$-amphetamine alone $(F(1,5)=21.87, P<0.0001)$ (Figure $6 \mathrm{~b}$ ).

Finally, we have verified that RS by itself was not inducing sensitization. Indeed, $d$-amphetamine-induced extracellular NE levels after repeated RS102221 were not significantly different from that obtained after repeated saline $(\mathrm{F}(1,24)=1.039, P=0.3181)$ and the $d$-amphetamine-induced extracellular NE levels after repeated $d$-amphetamine were not significantly different from that obtained after repeated RS102221 $+d$-amphetamine $(\mathrm{F}(1,24)=2.011$, 
$P=0.1690$ ) (Figure 6a). Moreover, locomotor activity induced by $d$-amphetamine was not significantly different in animals pretreated with repeated RS102221 and in those pretreated with saline $(F(1,147)=0.9312, P=0.3361)$ as well as in those pretreated with $d$-amphetamine + RS102221 or saline $+d$-amphetamine $(F(1,147)=3.677, \quad P=0.0571)$ (Figure 6b).

\section{DISCUSSION}

We show here not only that exposure to cocaine, morphine, or ethanol increases cortical noradrenergic and serotonergic responding after 4-day withdrawal, but also that the enhanced cortical NE and 5-HT neurochemical responses to $d$-amphetamine and PCA, respectively, can be prevented by administering $\alpha 1 \mathrm{~b}$-adrenergic and $5-\mathrm{HT}_{2 \mathrm{~A}}$ receptor antagonists during exposure to these three drugs of abuse. Our data further indicate that repeated exposure to cocaine, morphine, or ethanol induces increased locomotor responses to $d$-amphetamine and PCA and that the development of this behavioral sensitization is blocked by pretreatment with the same receptor antagonists. Moreover, cortical NE and 5-HT increased responding occurs, as well as the increased behavioral response, few days after the last drug injection, unlike data obtained by others showing that nucleus accumbens DA responding is enhanced weeks but not days after drug exposure (see review by Paulson and Robinson, 1995). The absence of correlation between the development of increased DA responding in the nucleus accumbens and behavioral sensitization may be due to the release by $d$-amphetamine of an important part of nonfunctional DA, that is impulse flow-independent and not related to locomotor activity (Darracq et al, 1998). A correlation between cortical increased $\mathrm{NE}$ responding would occur because $d$-amphetamine releases in the frontal cortex an important part of functional NE, that is impulseflow dependent (Florin et al, 1994) and therefore more related to a behavioral response. It is conceivable that sensitization of noradrenergic neurons impacts on dopaminergic neurons innervating subcortical structures but that this sensitization is masked in the first days of withdrawal by a decrease of the non-functional part of DA (Segal and Kuczenski, 1992; Darracq et al, 1998). Interestingly, repeated treatments with two antidepressants from two different classes, clorimipramine and venlafaxine, do not induce sensitized cortical noradrenergic or serotonergic responding, although both of them stimulate acutely noradrenergic and serotonergic transmissions.

Our data therefore show that the mutual regulation of noradrenergic and serotonergic neurons is impaired by repeated treatments with drugs of abuse as diverse as $d$-amphetamine, cocaine, morphine, or ethanol. Together with previous behavioral data obtained with amphetamine, cocaine, and morphine (Auclair et al, 2004), the inhibiting effects of the $\alpha 1 \mathrm{~b}$-adrenergic and $5-\mathrm{HT}_{2 \mathrm{~A}}$ receptor antagonists on uncoupling between noradrenergic and serotonergic neurons suggest that the mechanisms responsible for this phenomenon are similar whatever be the drug of abuse. Our data seem particularly interesting when one considers the different pharmacology of the four substances tested thus far. $d$-Amphetamine is a catecholamine releaser and cocaine blocks 5-HT, NE, and DA reuptake activity. Morphine inhibits noradrenergic neurons (Korf et al, 1974) and disinhibits midbrain DA and serotonin cell firing via the stimulation of $\mu$-opiate receptors located on GABAergic interneurons (Johnson and North, 1992; Jolas and Aghajanian, 1997; Tao and Auerbach, 2002). Finally, ethanol enhances GABAA receptor-mediated inhibitory postsynaptic currents and reduces NMDA receptormediated excitatory postsynaptic currents (Nestoros, 1980; Lovinger et al, 1989). It possesses monoamine oxidase inhibiting properties via its metabolite acetaldehyde and increases extracellular 5-HT and DA levels in the nucleus accumbens (Di Chiara and Imperato, 1988; Yoshimoto et al, 1992). Once again, this strongly suggests that, although neurochemical mechanisms of drugs of abuse are obviously different, NE-5-HT uncoupling is a central phenomenon in the effects of the repeated consumption of drugs of abuse. Data obtained with prazosin and SR46349B suggest that NE-5-HT uncoupling is, whatever the initial effects of the drug of abuse, the consequence of a repeated stimulation of $\alpha 1 \mathrm{~b}$-adrenergic and $5-\mathrm{HT}_{2 \mathrm{~A}}$ receptors.

One of the evidence that led us to propose the existence of a NE-5-HT coupling is that $\alpha 1 \mathrm{~b}$-adrenergic receptor knockout mice were found to exhibit enhanced behavioral and neurochemical (cortical extracellular 5-HT levels) responses to PCA and that, reciprocally, $5-\mathrm{HT}_{2 \mathrm{~A}}$ receptor knockout mice exhibited increased behavioral and neurochemical (cortical extracellular NE levels) responses to $d$-amphetamine (Salomon et al, 2006). As suggested above, because prazosin and SR46349B prevent uncoupling, it may be proposed that drugs of abuse produce this effect by increasing extracellular NE and/or 5-HT levels. However, this property does not seem sufficient because venlafaxine and clorimipramine, two non-addictive compounds, block both NE and 5-HT reuptake activity, thus increasing extracellular NE and 5-HT levels, but nevertheless do not induce increased sensitivity of noradrenergic and serotonergic neurons nor behavioral sensitization (Mitchell et al, 2006 and data not shown). It is tempting to propose that differences between the two groups of addictive and nonaddictive substances are related to differing abilities to increase extracellular DA levels. However, repeated treatments with a high dose of GBR12783, a specific inhibitor of DA reuptake, do not induce uncoupling. This finding is in agreement with our previous data indicating that in the rat, GBR12783 induces locomotor hyperactivity but no behavioral sensitization (Drouin et al, 2002a). Therefore, an increase in extracellular DA levels may be important to trigger a locomotor activation but not sufficient to induce NE-5-HT uncoupling and behavioral sensitization. Moreover, when treating repeatedly animals with a mixture of GBR12783 (20 mg/kg) and venlafaxine $(20 \mathrm{mg} / \mathrm{kg})$ no sensitization of noradrenergic and serotonergic neurons occurred (data not shown). At that point, a paradox still remained because, although D1 or/and D2 receptors antagonists failed to block the development of behavioral sensitization to cocaine (White et al, 1998) and morphine (Jeziorski and White, 1995), blockade of D1 receptors by SCH23390 was shown to inhibit the development of behavioral sensitization to $d$-amphetamine (Vezina, 1996). Moreover, we had also shown that pretreatment with SCH23390 prevents NE-5-HT uncoupling induced by 
$d$-amphetamine (Salomon et al, 2006). We show now that the effects of $\mathrm{SCH} 23390$ are related to its potent $5-\mathrm{HT}_{2 \mathrm{C}}$ agonist property (Millan et al, 2001b). Indeed, SCH23390 blocks the $d$-amphetamine-induced increase in cortical extracellular NE levels, a blockade which is completely reversed by the $5-\mathrm{HT}_{2 \mathrm{C}}$ receptor antagonist, RS102221. The same compound, RS102221, is also able to reverse the blockade by SCH23390 of the development of behavioral sensitization to $d$-amphetamine as well as the noradrenergic neurons sensitization. Moreover, it should be emphasized that, although RS102221 is able to reverse the effects of SCH23390 on the induction of $d$-amphetamine behavioral sensitization, it does not reverse the expression of behavioral sensitization (data not shown). This confirms that D1 receptors stimulation is nevertheless necessary for the expression of behavioral sensitization to $d$-amphetamine (Vezina, 1996). Altogether, it seems that it is the stimulation of noradrenergic transmission, rather than that of dopaminergic one, which is related to the development of NE-5-HT uncoupling and/or behavioral sensitization, a remark that disagrees with the role generally assigned to DA in the addictive process. Indeed, GBR12783, which increases extracellular DA levels but does not induce uncoupling, has no effect on cortical extracellular NE levels, even at high doses (data not shown). On the contrary, amineptine, an antidepressant that blocks DA reuptake and had to be withdrawn in France because of its addictive properties, was shown to be also a potent NE releaser (Garattini et al, 1997; Garattini, 1997). An increase in extracellular NE levels would nevertheless be necessary but not sufficient to induce uncoupling. Indeed, clorimipramine and venlafaxine, two non-addictive antidepressants, which both increase extracellular NE and 5-HT levels (Millan et al, 2001a), do not induce uncoupling. This may signify either that drugs of abuse possess a yet unknown common property necessary to induce uncoupling or that non-addictive antidepressants, or their metabolites, exhibit intrinsic pharmacological characteristics, which limit noradrenergic and/or serotonergic transmission. For example, concomitant anti- $\alpha 1-$ adrenergic or $5-\mathrm{HT}_{2 \mathrm{~A}}$ and $5-\mathrm{HT}_{2 \mathrm{C}}$ antagonist or agonist properties (Dekeyne and Millan, 2003; Van Oekelen et al, 2003) may block the development of uncoupling and behavioral sensitization. It is also possible that noradrenergic and serotonergic neurons sensitization only occurs following short and intense repeated stimulations of $\alpha 1 b$ adrenergic and $5-\mathrm{HT}_{2 \mathrm{~A}}$ receptors, whereas antidepressants induce only slow and moderate increase in noradrenergic and serotonergic transmissions.

This sensitization of noradrenergic and serotonergic neurons may be related with a modification in gene expression in the nucleus accumbens (Hyman and Malenka, 2001; Nestler, 2001), but also, as suggested by our data, in other structures such as the locus coeruleus and the raphe nuclei. Anatomical and functional studies between these two latter nuclei indicate that the discharge rate of serotonergic neurons is under the excitatory control of $\alpha 1$-adrenergic receptors (Baraban and Aghajanian, 1980; Bortolozzi and Artigas, 2003) and, conversely, that serotonergic cells in raphe nuclei hyperpolarize noradrenergic cells in the locus coeruleus by stimulating $5-\mathrm{HT}_{2 \mathrm{~A}}$ receptors on GABAergic interneurons (Szabo and Blier, 2001). Another non-exclusive possibility is that coupling between both neurotrans- mitter systems occurs in the prefrontal cortex where $\alpha 1 \mathrm{~b}$-adrenergic and $5-\mathrm{HT}_{2 \mathrm{~A}}$ receptors are colocalized (Marek and Aghajanian, 1999; Salomon et al, 2006) and thus control noradrenergic and serotonergic mesencephalic nuclei (Gobert and Millan, 1999; Amargos-Bosch et al, 2003). Increased cortical extracellular NE and 5-HT levels would stimulate glutamatergic pyramidal cells (Sesack and Pickel, 1992), which excite ventral tegmental area (VTA) dopaminergic neurons or project directly to the nucleus accumbens (Pierce et al, 1996) and thus increase locomotor activity. Behavioral sensitization has also been observed following local bilateral injection of $d$-amphetamine into the VTA. This behavioral sensitization is blocked by local or systemic SCH23390 injection (Vezina, 1996). We have not tested if local injection of $d$-amphetamine was also inducing a NE-5-HT uncoupling. Such an experiment would be interesting to determine whether both types of behavioral sensitization, that is induced by systemic or local VTA $d$ amphetamine, induce the same neural adaptations.

The consequence of uncoupling, as displayed by $d$-amphetamine and PCA, is an increased reactivity of noradrenergic and serotonergic neurons. As found with $d$-amphetamine (Salomon et al, 2006), it is very likely, although not shown here, that the NE-5-HT uncoupling induced by cocaine, morphine, and ethanol is long lasting. In non-addicts, because of the mutual regulation between noradrenergic and serotonergic neurons, the amplitude of the activation of one set of neurons induced by peripheral stimuli would be limited by the other group. In human addicts, because of uncoupling, each group of neurons would react to external stimuli as if they were independent and undergo not only higher but also probably desynchronized activations, thus inducing discomfort and distress. Mechanism of uncoupling could be conceptualized as the physiological response of a neuronal network to the effects of repeated injections of drugs of abuse. If one assumes that this adaptation is a homeostatic response, drugs of abuse would drive the neuronal network into a state where the neural link between noradrenergic and serotonergic neurons is no longer functional. Therefore, human addicts would relapse in order to return to a state that, at least temporarily, relieve them from the consequences of the chronic absence of coupling they have endured, a condition that drug consumption would facilitate. We propose that human addicts are vulnerable to relapse because of the NE-5-HT uncoupling, which seems directly related to rodent's behavioral sensitization. Behavioral sensitization can last up to 1 year (Paulson et al, 1991), but also may decrease after withdrawal (Villegier et al, 2003), suggesting that uncoupling is, as mentioned earlier, long lasting but, in some cases, reversible; future therapeutic treatments of addiction should therefore aim at developing new compounds that accelerate re-coupling of noradrenergic and serotonergic neurons.

\section{ACKNOWLEDGEMENTS}

We thank G Blanc and G Godeheu for skilful technical assistance. This work was supported by Inserm and MILDT (Mission interministérielle de lutte contre les drogues et les toxicomanies). 


\section{DISCLOSURE/CONFLICT OF INTEREST}

The authors declare that, except from income received from our primary employers, no financial support or compensation has been received from any individual or corporate entity over the past 3 years for research or professional service and there are no personal financial holdings that could be perceived as constituting a potential conflict of interest.

\section{REFERENCES}

Amargos-Bosch M, Adell A, Bortolozzi A, Artigas F (2003). Stimulation of alpha1-adrenoceptors in the rat medial prefrontal cortex increases the local in vivo 5-hydroxytryptamine release: reversal by antipsychotic drugs. J Neurochem 87: 831-842.

Auclair A, Drouin C, Cotecchia S, Glowinski J, Tassin J-P (2004). $\mathrm{D} 1$ dopamine receptor activation is necessary for the induction of sensitization by amphetamine in the ventral tegmental area. Eur J Neurosci 20: 3073-3084.

Baraban JM, Aghajanian GK (1980). Suppression of firing activity of 5-HT neurons in the dorsal raphe by alpha-adrenoceptor antagonists. Neuropharmacology 19: 355-363.

Bonhaus DW, Flippin LA, Greenhouse RJ, Jaime S, Rocha C, Dawson $M$ et al (1997). RS-102221: a novel high affinity and selective, $5-\mathrm{HT}_{2 \mathrm{C}}$ receptor antagonist. Neuropharmacology 36: 621-629.

Bortolozzi A, Artigas F (2003). Control of 5-hydroxytryptamine release in the dorsal raphe nucleus by the noradrenergic system in rat brain. Role of alpha-adrenoceptors. Neuropsychopharmacology 28: 421-434.

Conductier G, Crosson C, Hen R, Bockaert J, Compan V (2005). $3,4-N$-methlenedioxymethamphetamine-induced hypophagia is maintained in 5-HT1B receptor knockout mice, but suppressed by the 5-HT2C receptor antagonist RS102221. Neuropsychopharmacology 30: 1056-1063.

Darracq L, Blanc G, Glowinski J, Tassin JP (1998). Importance of the noradrenaline-dopamine coupling in the locomotor activating effects of D-amphetamine. J Neurosci 18: 2729-2739.

Dekeyne A, Millan MJ (2003). Discriminative stimulus properties of antidepressant agents: a review. Behav Pharmacol 14: 391-407.

Di Chiara G, Imperato I (1988). Drugs abused by humans preferentially increase synaptic dopamine concentrations in the mesolimbic system of freely moving rats. Proc Natl Acad Sci USA 85: 5274-5278.

Drouin C, Blanc G, Villegier AS, Glowinski J, Tassin J-P (2002a). Critical role of alpha1-adrenergic receptors in acute and sensitized locomotor effects of D-amphetamine, cocaine, and GBR 12783: influence of preexposure conditions and pharmacological characteristics. Synapse 43: 51-61.

Drouin C, Darracq L, Trovero F, Blanc G, Glowinski J, Cotecchia S et al (2002b). Alpha1b-adrenergic receptors control locomotor and rewarding effects of psychostimulants and opiates. J Neurosci 22: 2873-2884.

Everitt BJ, Wolf ME (2002). Psychomotor stimulant addiction: a neural systems perspective. J Neurosci 22: 3312-3320.

Florin SM, Kuczenski R, Segal DS (1994). Regional extracellular norepinephrine responses to amphetamine and cocaine and effects of clonidine pretreatment. Brain Res 654: 53-62.

Garattini S (1997). Pharmacology of amineptine, an antidepressant agent acting on the dopaminergic system: a review. Int Clin Psychopharmacol 12: 15-19.

Gobert A, Millan MJ (1999). Serotonin (5-HT)2A receptor activation enhances dialysate levels of dopamine and noradrenaline, but not 5-HT, in the frontal cortex of freely-moving rats. Neuropharmacology 38: 315-317.
Hamamura T, Akiyama K, Akimoto K, Kashihara K, Okumura K, Ujike H et al (1991). Co-administration of either a selective D1 or D2 dopamine antagonist with methamphetamine prevents methamphetamine-induced behavioral sensitization and neurochemical change, studied by in vivo intracerebral dialysis. Brain Res 546: 40-46.

Hnasko TS, Sotak BN, Palmiter RD (2005). Morphine reward in dopamine-deficient mice. Nature 438: 854-857.

Hyman SE, Malenka RC (2001). Addiction and the brain: the neurobiology of compulsion and its persistence. Nat Rev Neurosci 2: 695-703.

Itzhak Y, Achat-Mendes CN, Ali SF, Anderson KL (2004). Longlasting behavioral sensitization to psychostimulants following $p$-chloroamphetamine-induced neurotoxicity in mice. Neuropharmacology 46: 74-84.

Jeziorski M, White FJ (1995). Dopamine receptor antagonists prevent expression, but not development, of morphine sensitization. Eur J Pharmacol 275: 235-244.

Johnson SW, North RA (1992). Opioids excite dopamine neurons by hyperpolarization of local interneurons. J Neurosci 12: $483-488$.

Jolas T, Aghajanian GK (1997). Opioids suppress spontaneous and NMDA-induced inhibitory postsynaptic currents in the dorsal raphe nucleus of the rat in vitro. Brain Res 755: 229-245.

Koob GF, Sanna PP, Bloom FE (1998). Neuroscience of addiction. Neuron 21: 467-476.

Korf J, Bunney BS, Aghajanian GK (1974). Noradrenergic neurons: morphine inhibition of spontaneous activity. Eur J Pharmacol 25: 165-169.

Lovinger DM, White G, Weight FF (1989). Ethanol inhibits NMDAactivated ion current in hippocampal neurons. Science 243: 1721-1724.

Marek GJ, Aghajanian GK (1999). 5- $\mathrm{HT}_{2 \mathrm{~A}}$ receptor or alpha1adrenoceptor activation induces excitatory postsynaptic currents in layer $\mathrm{V}$ pyramidal cells of the medial prefrontal cortex. Europ J Pharmacol 367: 97-206.

Millan MJ, Dekeyne A, Papp M, La Rochelle CD, MacSweeny C, Peglion JL et al (2001a). S33005, a novel ligand at both serotonin and norepinephrine transporters: II. Behavioral profile in comparison with venlafaxine, reboxetine, citalopram, and clomipramine. J Pharmacol Exp Ther 298: 565-580.

Millan MJ, Newman-Tancredi A, Quentric Y, Cussac D (2001b). The 'selective' dopamine D1 receptor antagonist, $\mathrm{SCH} 23390$, is a potent and high efficacy agonist at cloned human serotonin2C receptors. Psychopharmacology (Berlin) 156: 58-62.

Mitchell HA, Ahern TH, Liles LC, Javors MA, Weinshenker D (2006). The effects of norepinephrine transporter inactivation on locomotor activity in mice. Biol Psychiatry 60: 1046-1052.

Nestler EJ (2001). Molecular basis of long-term underlying addiction. Nat Rev Neurosci 2: 119-128.

Nestoros JN (1980). Ethanol specifically potentiates GABAmediated neurotransmission in feline cerebral cortex. Science 209: 708-710.

Olson VG, Heusner CL, Bland RJ, During MJ, Weinshenker D, Palmiter RD (2006). Role of noradrenergic signaling by the nucleus tractus solitarius in mediating opiate reward. Science 311: 1017-1020.

Paulson PE, Camp DM, Robinson TE (1991). Time course of transient behavioral depression and persistent behavioral sensitization in relation to regional brain monoamine concentrations during amphetamine withdrawal in rats. Psychopharmacology (Berlin) 103: 480-492.

Paulson PE, Robinson TE (1995). Amphetamine-induced timedependent sensitization of dopamine neurotransmission in the dorsal and ventral striatum: a microdialysis study in behaving rats. Synapse 19: 56-65.

Paxinos G, Franklin KBJ (2001). The Mouse Brain in Stereotaxic Coordinates, 2nd edn. Academic Press: San Diego, USA. 
Pierce RC, Bell K, Duffy P, Kalivas PW (1996). Repeated cocaine augments excitatory amino acid transmission in the nucleus accumbens only in rats having developed behavioral sensitization. J Neurosci 16: 1550-1560.

Robinson TE, Berridge KC (1993). The neural basis of drug craving: an incentive-sensitization theory of addiction. Brain Res Rev 18: 247-291.

Robinson TE, Berridge KC (2000). The psychology and neurobiology of addiction: an incentive-sensitization view. Addiction 95: 91-117.

Salomon L, Lanteri C, Glowinski J, Tassin J-P (2006). Behavioral sensitization to amphetamine results from an uncoupling between noradrenergic and serotonergic neurons. Proc Natl Acad Sci USA 103: 7476-7481.

Segal DS, Kuczenski R (1992). In vivo microdialysis reveals a diminished amphetamine-induced DA response corresponding to behavioral sensitization produced by repeated amphetamine pretreatment. Brain Res 571: 330-337.

Sesack SR, Pickel VM (1992). Prefrontal cortical efferents in the rat synapse on unlabeled neuronal targets of catecholamine terminals in the nucleus accumbens septi and on dopamine neurons in the ventral tegmental area. J Comp Neurol 320: 145-160.

Szabo T, Blier P (2001). Functional and pharmacological characterization of the modulatory role of serotonin on the firing activity of locus coeruleus norepinephrine neurons. Brain Res 922: 9-20.

Tao R, Auerbach SG (2002). GABAergic and glutamatergic afferents in the dorsal raphe nucleus mediate morphine-induced increases in serotonin efflux in the rat central nervous system. J Pharmacol Exp Ther 303: 704-710.

Van Oekelen D, Luyten WH, Leysen J (2003). 5-HT2A and 5-HT2C receptors and their atypical regulation properties. Life Sci 72: 2429-2449.

Ventura R, Alcaro A, Puglisi-Allegra S (2005). Prefrontal cortical norepinephrine release is critical for morphine-induced reward, reinstatement and dopamine release in the nucleus accumbens. Cereb Cortex 15: 1877-1886.

Vezina P (1996). D1 dopamine receptor activation is necessary for the induction of sensitization by amphetamine in the ventral tegmental area. J Neurosci 68: 259-267.

Vezina P, Stewart J (1989). The effect of dopamine receptor blockade on the development of sensitization to the locomotor activating effects of amphetamine and morphine. Brain Res 499: $108-120$

Villegier AS, Blanc G, Glowinski J, Tassin J-P (2003). Transient behavioral sensitization to nicotine becomes long-lasting with monoamine oxidases inhibitors. Pharmacol Biochem Behav 76: 267-274.

White FJ, Joshi A, Koeltzow TE, Hu XT (1998). Dopamine receptor antagonists fail to prevent induction of cocaine sensitization. Neuropsychopharmacology 18: 26-40.

Wise RA (1998). Drug-activation of brain reward pathways. Drug Alcohol Depend 51: 13-22.

Yoshimoto K, McBride WJ, Lumeng L, Li TK (1992). Alcohol stimulates the release of dopamine and serotonin in the nucleus accumbens. Alcohol 9: 17-22. 